making it more than an organization that simply reacts to ideas from the community. He argues that a 'top-down' role for the DFG may be incompatible with its autonomy, a characteristic much acclaimed in the report.

Although the DFG does not oppose the principle of creating new programmes, Winnacker says "it is important that these are selected either by the research community itself, or in an interplay between DFG staff and the research community".

The report recognizes that the work of the DFG has grown enormously over the past decade, increasing the burden on DFG staff and their referees, and it recommends that the number of elected referees be increased by a quarter.

This suggestion, which is already being implemented by the DFG, is particularly welcome, says Klaus-Peter Hoffmann, professor of zoology and neurobiology at the University of Bochum, and a biology referee for the DFG for 25 years. Hoffmann receives 300 grants to review every year, and says the pressure crushes creativity. "When overburdened, one tends to shy away from risk, and this is one reason we have tended to avoid entering new territory," he says.

The MPS, while praised for the quality of its research, comes in for criticism for being "isolated from the university system" and for sticking too closely to the "Harnack princi- ple' on which it is based. This principle causes research to be concentrated in institutes headed by directors selected for their scientific stature rather than their research area.

Directors are appointed for life, receive generous support for their research and have complete freedom to choose the direction of their research. But the report says that this could hamstring the society by tying up too many resources in a single person for decades.

The report also calls for "International Max Planck Research Schools" to be created at universities to allow graduates to benefit from the expertise of local Max Planck institutes. It says that time-limited Max Planck research units should be created at universities. Both measures, it says, would help bring the MPS and universities into closer contact.

Although Markl supports cooperation with universities, he questions whether the committee, who did not review university research, was aware of the close cooperation that already exists in some places. He points out, for example, that "ten per cent of MPS directors now have university chairs".

But Axel Ullrich, a director of the Max Planck Institute for Biochemistry, near Munich, says that the current links are patchy and dependent on personal contacts. Ullrich has not been made a university professor, because most of his career was spent in the
United States, "so I was not established in academic circles in Munich". He welcomes closer contact between the two institutions.

Markl is in favour of international research schools. But he is "not yet sure" of the value of creating Max Planck groups in universities, as this moves away from the Harnack principle and, he says, could stretch resources too thinly.

Markl says that reforms will have to be paid for out of the five per cent annual budget increase promised by the German gov-

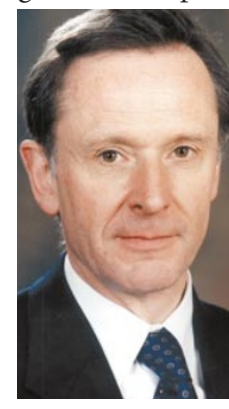

Brook: backs 'topdown' guidance. ernment for the next few years. "My first priority is to complete our plans for building up MPS activities in East Germany," he says. Future reforms will depend on whether the MPS can afford them.

Richard Brook, head of Britain's Engineering and Physical Sciences Research Council and chair of the committee, says that the MPS and DFG need to become more accessible to young scientists and women - "we were shocked to realize that only three per cent of MPS directors are women". Brook also says that the DFG should not necessarily be afraid of giving 'top-down' guidance. Alison Abbott\& QuirinSchiermeier

\title{
Proceed with caution, says UK report on ethics of GM foods
}

[LONDON] Last month's decision by the British government to strengthen the monitoring of genetically modified (GM) foods but resist calls for a moratorium on their commercial planting has been implicitly endorsed by the main UK bioethics advisory body (see Nature 399, 287; 1999).

In a report published last week, the Nuffield Council on Bioethics says that there are many aspects of the development and introduction of GM foods that warrant firm government action (see page 405 in this issue). These range from steps to limit the breadth of patent claims to what it describes as a "moral imperative" to develop GM staple foods for the Third World.

But the report dismisses opposition to GM crops based either on broad claims about their 'unnaturalness' or on their potential for misuse. The genetic modification of crop plants, it says, "does not differ to such an extent from conventional plant breeding or other human interventions with the natural world as to make the process morally objectionable in itself".

The overall message has been welcomed by the agrobiotech industry and the government. Jack Cunningham, the cabinet minister responsible for the government initiatives, said the report was "independent backing for the government's approach”.
The response has been cooler from environmentalist, Third World and religious groups, upset that the report's admittedly utilitarian stance does not pay closer heed to the ways that GM technology has been and is likely to be - used.

The report, Genetically Modifed Crops: The Ethical and Social Issues, was drawn up by a working party chaired by Alan Ryan, professor of philosophy at the University of Oxford. It outlines three areas in which, it claims, moral considerations are relevant: general welfare, people's rights (for example, to freedom of choice as consumers) and the principle of justice - the fair sharing of burdens and benefits.

From this perspective, while endorsing the patenting of genetic sequences, it urges national and international patent bodies to discourage patents "which allow extensive control over a single crop species," and to draw up new guidelines for doing so.

The report also strongly endorses the use of GM crops in the Third World, arguing that the British government should allocate a "substantial amount" of its increased aid budget to research and development on GM food staples grown in developing countries.

But it also urges careful attention to the potential environmental impacts of GM crops, as well as to ensuring that farmers in these countries are given a choice between GM crops and traditional varieties.

By sticking to its three ethical principles, the working group rejects the demands of some critics to take a broader ethical stance. "It is the deleterious consequences of our farming techniques to our environment and public health, not their 'unnatural' character that should preoccupy us," the working group says.

Thus, although supporting in principle the labelling of GM foods, it opposes labelling as "not necessary or practical" for foods produced by a GM process where no difference can be detected.

The Third World group Christian Aid, which recently issued a report arguing that GM crops were unnecessary for problems that could be resolved by better food distribution (see Nature 399, 99; 1999), claimed that the council was "out of touch" with the real causes of hunger.

Donald Bruce, who heads a project on GM foods for the Church of Scotland, says that although he agrees with much of the working party's conclusions, the report's dismissal of the 'unnaturalist' position is "a dogma rather than a serious argument".

But Ryan defends the working party, saying that the report "is intended to be read in a highly pluralistic society”. David Dickson 